\title{
Tandem Mass Spectrum of a Growth Hormone Secretagogue: Amide Bond Cleavage and Resultant Gas-Phase Rearrangement
}

\author{
Xue-Zhi Qin \\ Pharmaceutical Research, Merck Research Laboratories, West Point, Pennsylvania, USA
}

Compound $\quad \mathbf{1}\{\mathrm{N}-[1(\mathrm{R}) \quad-$ [(1,2-dihydro-1-methylsulfonylspiro[3H-indole-3,4'-piperidin]1'-yl)carbonyl]-2-(phenylmethyloxy)ethyl]-2-amino-2-methylpropanamide\}(MW 528) is an orally-active growth hormone secretagogue (GHS). As part of a continual effort to analyze the ESI/MS and $\mathrm{MS}^{n}$ data of novel drugs, the ESI/MS and MS/MS data of protonated $1(\mathrm{~m} / \mathrm{z} 529)$ are analyzed and reported here. The analyses reveal that under low-energy collision-induced dissociation (CID) in an ion trap or a quadrupole collision cell, protonated $\mathbf{1}$ undergoes a gas-phase rearrangement to form protonated $3(\mathrm{~m} / z$ 357) which competes with the y- and b-type product ions during the amide bond cleavages of protonated 1 . It is proposed that when the b-type ion is formed by cleavage of the piperidine amide bond, piperidine (a neutral species) and the b-ion (a cation) form an ion-neutral complex. In this complex, piperidine functions as a nucleophile to attack the benzylic carbon of the b-ion, and the protonated ether group in the b-ion acts as a leaving group, which results in the migration of the benzylic group to the piperidine amine to form protonated 3 . Protonated $\mathbf{2}$ (an analog of $\mathbf{1}$ ) was studied under the same experimental conditions. The results show that protonated 2 undergoes a similar rearrangement to form protonated 3 . While this rearrangement is a relatively minor fragmentation process for protonated $\mathbf{1}$, it is a predominant process for protonated $\mathbf{2}$. This phenomenon is explained in terms of the proposed ion-neutral-complex mechanism. (J Am Soc Mass Spectrom 2002, 13, 371-377) (C) 2002 American Society for Mass Spectrometry

C ompound 1 \{N-[1(R) - [(1,2-dihydro-1methylsulfonylspiro[3H-indole-3,4'-piperidin]1'-yl)carbonyl]-2-(phenylmethyloxy)ethyl]2-amino-2-methylpropanamide\} (MW 528) is an orallyactive growth hormone secretagogue (GHS). It has two amide bonds and can be considered to be a modified dipeptide. This compound has been evaluated in clinical studies as a potential alternative to $\mathrm{GH}$ replacement therapy [1].

Recently, electrospray ionization mass spectrometry (ESI/MS) and tandem mass spectrometry $\left(\mathrm{MS}^{n}\right)$ have been applied to many areas of drug discovery and development $[2,3]$. The successful application of these techniques requires a thorough understanding of the $\mathrm{ESI} / \mathrm{MS}$ and $\mathrm{MS}^{n}$ data of the drugs under investigation. As part of a continual analysis of the ESI/MS and $\mathrm{MS}^{n}$ data of representative, diverse drugs [4-8], the MS/MS data of protonated $\mathbf{1}$ are analyzed in detail in this report. Although LC/MS/MS has been applied to the determination of this compound in human plasma, the MS/MS data have not been carefully analyzed [9]. Previous studies [4-8] have demonstrated that novel

Published online March 1, 2002

Address reprint requests to Dr. X.-Z. Qin, Pharmaceutical Research, Merck Research Laboratories, WP78-302, West Point, PA 19486, USA. E-mail: zuezhi_qin@merck.com drugs could have novel gas-phase chemistry. Indeed, the analysis of the MS/MS data of protonated 1 unveils some of the remarkable gas-phase chemistry of protonated 1, which includes a gas-phase rearrangement that
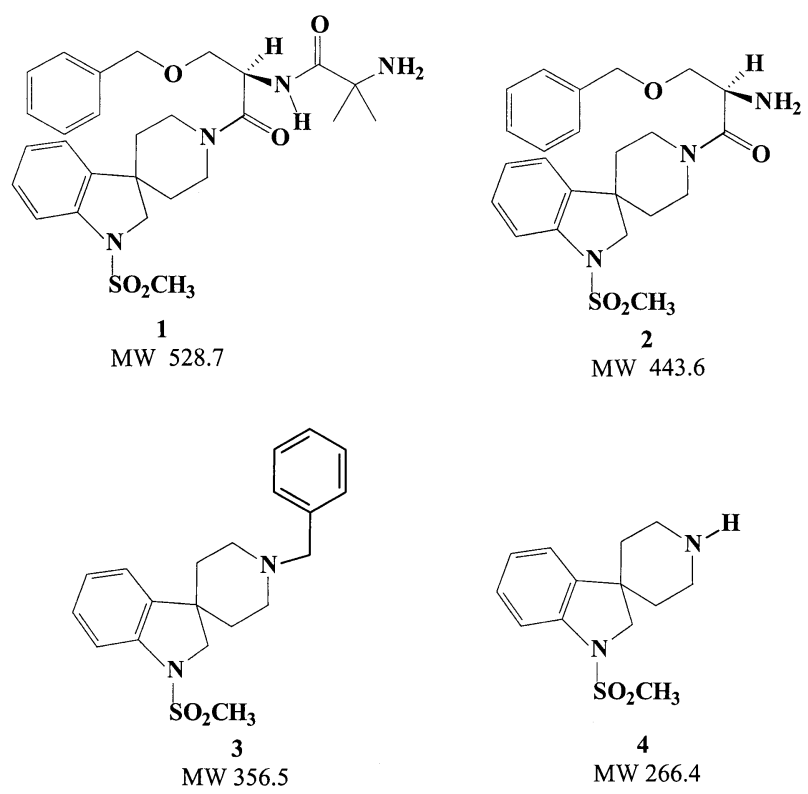

Structures 1-4 
competes with the formation of $y$ - and b-type ions during the cleavage of the amide bonds of this ion.

It is well-known that protonated ions often undergo gas-phase rearrangement [10]. For example, benzyl group migration from benzyloxycarbonyl to amidic nitrogens in CID of protonated peptides with Boc protecting groups has been documented [11, 12]. Several mechanisms have been proposed, such as a cyclic transition state in which an amide nitrogen attacks the benzylic carbon as a nucleophile [11] and a nominal four-membered-ring intermediate [12]. More recently, a novel gas-phase rearrangement of a farnesyl transferase inhibitor shown in eq 1 has been reported [8]. It has been proposed that this rearrangement (migration of a substituted benzyl group) is initiated by gas-phase intramolecular nucleophilic displacement [8].

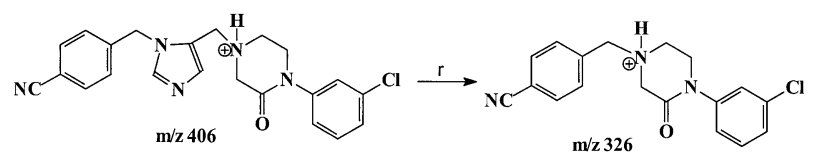

In this study, another remarkable gas-phase rearrangement involving benzyl group migration is described. In MS/MS experiments with a quadrupole ion trap or a collision cell of a quadrupole time-of-flight (Q-TOF) instrument, protonated $1(\mathrm{~m} / \mathrm{z} 529)$ and its analog $2(\mathrm{~m} / \mathrm{z}$ 444) rearrange to protonated $3(\mathrm{~m} / \mathrm{z} 357)$. These results provide examples of benzyl group migration from ether groups to amidic nitrogens under low-energy CID, which have not been reported before. The rearrangement cannot be well explained by the above-mentioned mechanisms as described in recent literature. In the past two decades, ion-neutral complexes have been noted in many gas-phase rearrangements of organic ions [1315]. It is proposed that the rearrangements of protonated $\mathbf{1}$ and $\mathbf{2}$ also involve ion-neutral complexes, each of which contains a b-type ion and a neutral piperidine formed during the cleavage of the protonated piperidine amide bond. In the complexes, the piperidine functions as a nucleophile to attack the benzylic carbon of the b-type ion while protonated ether of the b-type ion acts as a leaving group, resulting in the migration of the benzylic group to the piperidine amine in protonated $\mathbf{1}$ and $\mathbf{2}$ to form $\mathbf{3}$.

Of note is the finding that the product ions of protonated $\mathbf{1}$ (or 2) formed in an ion trap are the same as the product ions formed in Q-TOF although the relative yield of each product ion varies between the two instruments. The rearrangement is more prominent in an ion trap; therefore, the rearrangement described in this paper is based on the results of an ion trap. The results from Q-TOF are also included to assist in interpretation because this instrument gives accurate mass measurement for product ions.

\section{Experimental}

The quadrupole ion trap experiments were performed using a Finnigan LCQ (San Jose, CA) instrument equipped with a Finnigan MAT electrospray interface in the positive ionization mode. After protonated ions were generated by electrospray and injected into the ion trap, the ions of the mass-to-charge ratio $(\mathrm{m} / \mathrm{z})$ of interest were isolated while all other ions were ejected from the ion trap before the $\mathrm{MS}^{n}$ stage of the experiment. The selected ions were then resonantly excited in the presence of helium (pressure about $10^{-5}$ torr) to effect CID. The CID conditions were $g_{z}=0.25$ and 30 $\mathrm{ms}$. The relative collision energy (or resonance energy) settings were 25 to $40 \%$. The collision energy was calibrated using the Finnigan procedure. The product ions formed from CID produced an MS/MS spectrum. $\mathrm{MS}^{n}$ experiments were conducted by isolating product ions of the desired $\mathrm{m} / \mathrm{z}$ from a previous state of MS/MS, and then resonantly exciting those ions. The product ions in these stages produced an $\mathrm{MS}^{n}$ spectrum.

The quadrupole time-of-flight experiments were performed using a Micromass (Manchester, UK) Q-TOF-2 spectrometer operated in an electrospray positive ion mode with the cone voltage at 30 volts. CID was carried out using argon as the collision gas with collision energies from 20 to $45 \mathrm{eV}$.

Compounds 1, 2, and 4 were obtained from Chemical Data of Merck Research Laboratories (Rahway, NJ), and used without further purification. Compound 3 was made by a reaction of $\mathbf{4}$ with benzyl bromide in DMF [16]. Compound 3 was verified by accurate mass measurement and proton NMR. The NMR data showed that the chemical shift ( $\delta) 4.8$ (singlet) for the methylene protons of benzyl bromide changed to $\delta 4.7$ (singlet) for the corresponding methylene protons of 3 while the NMR data for all the other protons of 4 and benzyl bromide were little changed in 3 .

The samples were prepared by dissolving approximately $5 \mathrm{mg}$ of each compound into $100 \mathrm{ml}$ water. Accordingly, the deuterated samples were prepared by dissolving $5 \mathrm{mg}$ of each compound into $100 \mathrm{ml} \mathrm{D}_{2} \mathrm{O}$.

The samples were delivered into the LCQ instrument or Micromass Q-TOF-2 instrument by infusion at 3 $\mu \mathrm{l} / \mathrm{min}$ using a Harvard Apparatus Pump 11.

\section{Results and Discussion}

\section{CID of Protonated 1}

A representative MS/MS spectrum of protonated $\mathbf{1}(\mathrm{m} / \mathrm{z}$ 529) obtained using Finnigan LCQ is depicted in Figure 1 , which shows six product ions at $\mathrm{m} / \mathrm{z} 444,357,267$, 263,235 , and 188. The proposed structures of these six product ions are shown in Scheme 1 . The structures are fully supported by the accurate masses obtained using Micromass QTOF-2. Table 1 shows the comparison of the masses determined by Micromass QTOF-2 and the actual masses of the proposed structures. The relative 


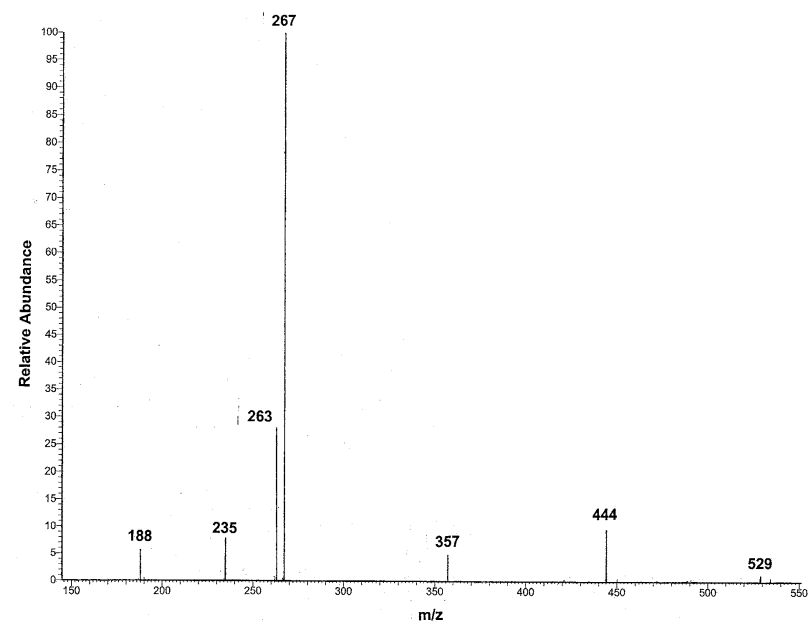

Figure 1. An ESI/MS/MS spectrum of protonated 1 obtained using Finnigan LCQ.

errors are all less than $10 \mathrm{ppm}$. The measurement was repeated five times and in all the measurements, the relative errors were found to be less than $10 \mathrm{ppm}$. Because the compositions of these product ions must be within the formula of protonated $1\left(\mathrm{C}_{0-27} \mathrm{H}_{0-37} \mathrm{~N}_{0-4} \mathrm{O}_{0-5} \mathrm{~S}_{0-1}\right)$, the compositions in terms of the accurate masses were calculated within this formula. The results indicate that

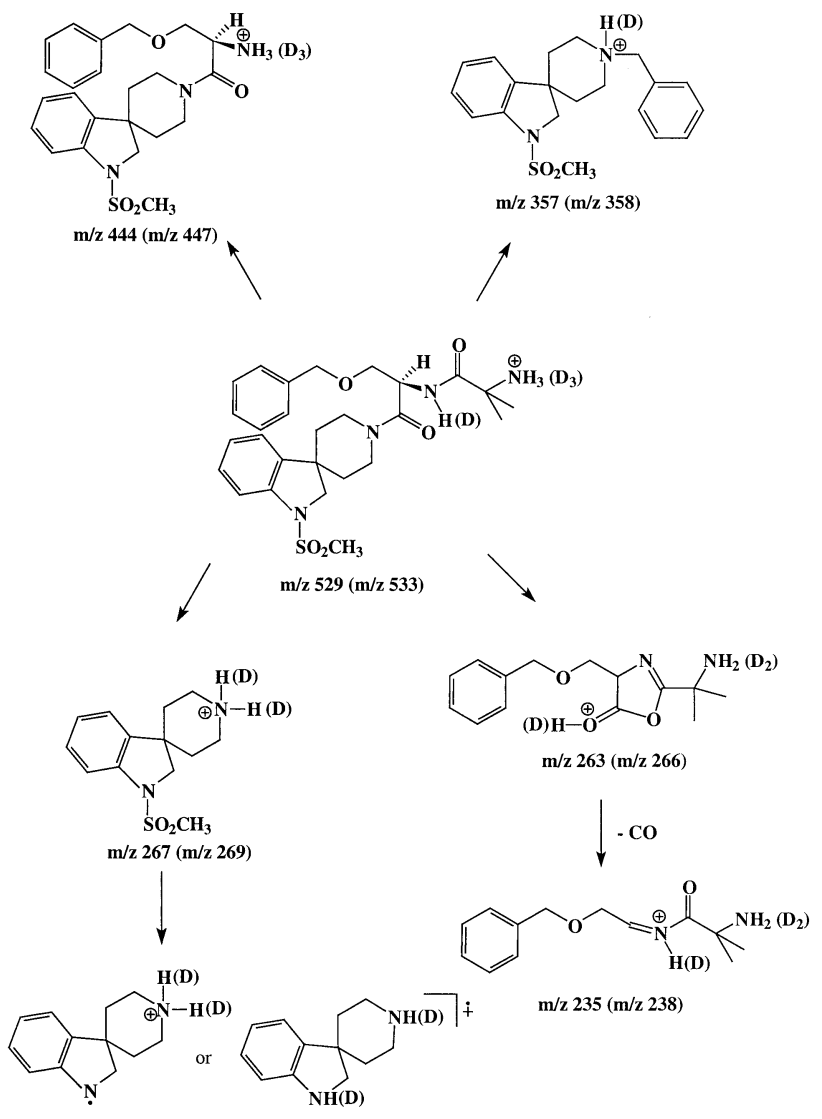

$\mathrm{m} / \mathbf{z} 188(\mathrm{~m} / \mathrm{z} 190)$

Scheme 1 Proposed structures for the six major product ions observed in MS/MS of protonated 1. The data in parentheses are those observed in MS/MS of deuterated 1.
Table 1. Comparison of accurate masses determined by Micromass QTOF-2 and actual masses for the proposed structures of the six product ions of protonated $\mathbf{1}\left(\mathrm{C}_{27} \mathrm{H}_{37} \mathrm{~N}_{4} \mathrm{O}_{5} \mathrm{~S}\right)$

\begin{tabular}{cccc}
\hline Product ions & Mass (QTOF-2) & Actual mass & Relative error \\
\hline \hline $\begin{array}{c}\mathrm{C}_{23} \mathrm{H}_{30} \mathrm{~N}_{3} \mathrm{O}_{4} \mathrm{~S} \\
(m / z 444)\end{array}$ & 444.1948 & 444.1957 & $-2 \mathrm{ppm}$ \\
$\mathrm{C}_{20} \mathrm{H}_{25} \mathrm{~N}_{2} \mathrm{O}_{2} \mathrm{~S}$ & 357.1650 & 357.1637 & $+4 \mathrm{ppm}$ \\
$(\mathrm{m} / \mathrm{z} 357)$ & & & \\
$\mathrm{C}_{13} \mathrm{H}_{19} \mathrm{~N}_{2} \mathrm{O}_{2} \mathrm{~S}$ & 267.1163 & 267.1167 & $-1 \mathrm{ppm}$ \\
$(m / z 267)$ & & & \\
$\mathrm{C}_{14} \mathrm{H}_{19} \mathrm{~N}_{2} \mathrm{O}_{3}$ & 263.1386 & 263.1396 & $-4 \mathrm{ppm}$ \\
$(m / z 263)$ & & & \\
$\mathrm{C}_{13} \mathrm{H}_{19} \mathrm{~N}_{2} \mathrm{O}_{2}$ & 235.1463 & 235.1447 & $+6 \mathrm{ppm}$ \\
$(m / z 235)$ & & & \\
$\mathrm{C}_{12} \mathrm{H}_{16} \mathrm{~N}_{2}$ & 188.1304 & 188.1313 & $-5 \mathrm{ppm}$ \\
$(\mathrm{m} / \mathrm{z} 188)$ & & & \\
\hline
\end{tabular}

the proposed structures have the only reasonable compositions.

The six product ions are formed by charge-induced competing processes which are dependent on protonation sites. Because compound $\mathbf{1}$ has a $\mathrm{pKa}$ value of 7.4 assigned to the primary amine, the initial protonation site should be at the primary amine. However, proton migration can occur upon CID, and other basic sites can be protonated according to the mobile proton hypothesis [17, 18]. The protonation of the amide group of 2-amino-2-methyl-propanamide results in the formation of the ion at $\mathrm{m} / \mathrm{z} 444$. The formation of this ion resembles that of a $y$-ion of a protonated peptide. The structure of this ion is confirmed by a match of the product ion spectra of this ion ( $\mathrm{MS}^{3}$ experiments) and the product ion spectra of protonated 2 (the neutral precursor of the ion at $m / z 444)\left(\mathrm{MS}^{2}\right.$ experiments). The protonation of the piperidine amide group gives rise to the ion at $\mathrm{m} / \mathrm{z} 267$ (also a y-ion formation mechanism). The structure of this ion is confirmed by a match of the product ion spectra of this ion ( $\mathrm{MS}^{3}$ experiments) and the product ion spectra of protonated 4 (the neutral precursor of the ion at $m / z 267)\left(\mathrm{MS}^{2}\right.$ experiments). The $\mathrm{MS}^{3}$ results of the ion at $\mathrm{m} / \mathrm{z} 267$ show that the ion at $\mathrm{m} / \mathrm{z}$ 188 is a major product ion of the ion at $\mathrm{m} / \mathrm{z} 267$. According to the accurate mass results (Table 1), the ion at $m / z 188$ is formed by the loss of the $\mathrm{SO}_{2} \mathrm{CH}_{3}$ radical from the ion at $m / z$ 267. Based on Proton Affinities (PAs), it is expected that the secondary amine, rather than the amide, of the ion at $\mathrm{m} / \mathrm{z} 267$ would be protonated. As a result, the $m / z 188$ ion would be a novel distonic radical ion with a separate nitrogen-centered cation and nitrogen-centered radical. However, if an H-migration from the amine to the amide occurred simultaneously with the homolytic cleavage of the S-N bond, an amine radical cation at $m / z 188$ would be formed. This H-migration seems less likely since the difference in PAs between the amine and the amide is estimated to be greater than $0.5 \mathrm{eV}\left(\right.$ or $50 \mathrm{kJmol}^{-1}$ ) [19], a proposed value beyond which $\mathrm{H}$-exchanges no longer occur in the unimolecular decomposition of protonated species $[20,21]$. When the piperidine amide is proton- 
Table 2. Comparison of the product ions of the ion at $\mathrm{m} / \mathrm{z} 357$ generated from source CID of protonated $\mathbf{1}$ and from its protonated neutral precursor (3)

\begin{tabular}{lccc}
\hline Product ions & Source CID & Protonated 3 & Difference \\
\hline \hline$m / z 278$ & 278.1793 & 278.1783 & $+1 \mathrm{mDa}$ \\
$m / z 221$ & 221.1202 & 221.1224 & $-2 \mathrm{mDa}$ \\
$m / z 187$ & 187.1237 & 187.1277 & $-4 \mathrm{mDa}$ \\
$m / z 170$ & 170.0980 & 170.0984 & $<1 \mathrm{mDa}$ \\
$m / z 144$ & 144.0799 & 144.0830 & $-3 \mathrm{mDa}$ \\
$m / z 131$ & 131.0769 & 131.0751 & $+2 \mathrm{mDa}$ \\
$m / z 91$ & 91.0541 & 91.0553 & $-1 \mathrm{mDa}$ \\
\hline
\end{tabular}

ated, a heterolytic $\mathrm{C}-\mathrm{N}$ bond cleavage of this group gives rise to the ion at $m / z 263$ by elimination of a neutral amine. The formation of this ion resembles a $b_{2}$-ion formation of protonated peptides. Since the dominant view favors the idea that $b_{2}$-ions have a fivemembered ring structure (protonated oxazolone) [22], the structure of the ion at $m / z 263$ is assigned to an oxazolonium cation. $\mathrm{MS}^{3}$ of the ion at $\mathrm{m} / \mathrm{z} 263$ yields an abundant ion at $\mathrm{m} / \mathrm{z} 235$ arising by $\mathrm{CO}$ loss and a smaller ion at $m / z 219$ arising by $\mathrm{CO}_{2}$ loss. These results provide strong evidence for the assignment. Particularly, the $\mathrm{CO}_{2}$ loss is considered to be diagnostic of a protonated oxazolone [23]. Loss of a CO group from the ion at $m / z 263$ produces the ion at $m / z 235$ (an a-type of ion).

In addition, there is a unique ion at $m / z 357$, which cannot be rationalized without invoking skeletal rearrangement. The proposed structure (protonated 3 ) for this ion is formed by the migration of the benzyl cation from the ether group to the piperidine amide nitrogen followed by the elimination of the keto with the rest of the molecule. The rearrangement, although a minor process, is significant since the rearrangement competes with the formations of $y$ - and b-ions. The rearrangement can become a predominant fragmentation process for analogs of $\mathbf{1}$ such as protonated protonated $\mathbf{2}$ (see below).

\section{CID of the Rearrangement Ion at $\mathrm{m} / \mathrm{z} 357$ and Protonated 3}

Convincing evidence for the structural assignment of the ion at $m / z 357$ comes from accurate mass measurements (by Micromass Q-TOF-2) of the product ions of this ion (generated by source CID of protonated 1) and
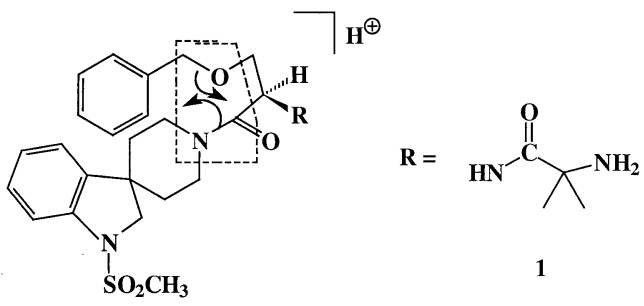

$\mathrm{NH}_{2}$ 2

Scheme 2 Nominal four-membered-ring transition state for the rearrangement of protonated 1 and 2 .

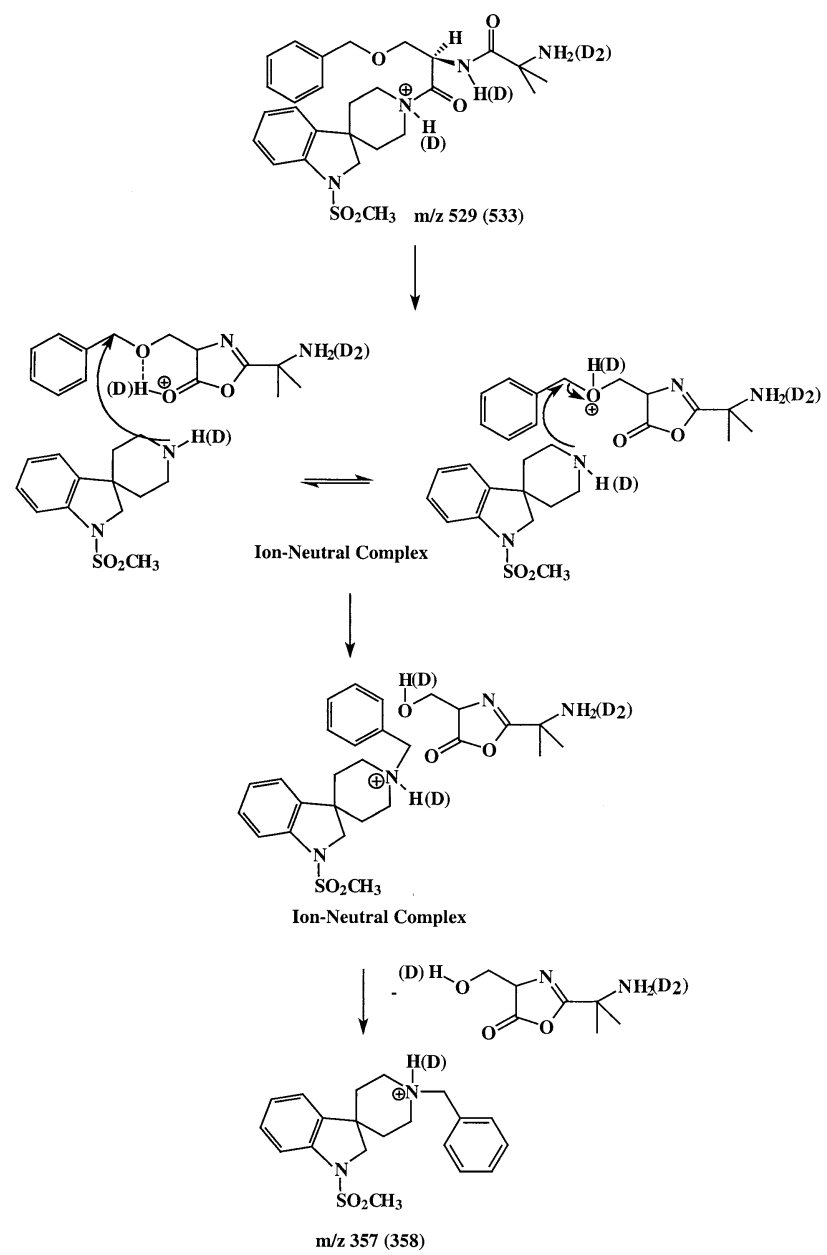

Scheme 3 A proposed rearrangement mechanism for the formation of the ion at $\mathrm{m} / \mathrm{z} 357$ from protonated 1. The data in parentheses are for deuterated $\mathbf{1}$.

protonated 3 (the neutral precursor of the ion at $\mathrm{m} / \mathrm{z}$ 357). Five measurements show that both the number and the accurate mass of the product ions of this ion are in excellent agreement with those of protonated 3. A set of measurement results of the main product ions are shown in Table 2 to demonstrate this point.

It is noteworthy that the accurate mass of the ion at $\mathrm{m} / \mathrm{z} 278$ indicates that it is formed from the loss of the $\mathrm{SO}_{2} \mathrm{CH}_{3}$ radical from the ion at $m / z$ 357. According to the accurate mass, the ion at $m / z 91$ has the elemental composition of $\mathrm{C}_{7} \mathrm{H}_{7}^{+}$, which is either the benzyl or its isomer-tropylium cation [24]. The presence of both $\mathrm{SO}_{2} \mathrm{CH}_{3}$ and benzyl groups in the ion at $\mathrm{m} / \mathrm{z} 357$ is consistent with the assigned structure of this ion.

\section{Proposed Rearrangement Pathway for Protonated 1}

The rearrangement of protonated 1 to the ion at $m / z 357$ appears to follow a four-membered-ring intermediate as shown in Scheme 2. This type of intermediate has been proposed to explain many other even-electron-ion rearrangements [10] as well as the benzyl group migration of protonated peptides with Boc protecting groups 
[12]. However, those intermediates are unfavorable with regard to orbital-symmetry considerations [25]. It has been noted that these rearrangements may proceed with involvement of ion-molecule complexes [20].

Another proposed mechanism for the rearrangement of protonated 1 to the ion at $\mathrm{m} / \mathrm{z} 357$ involves an intramolecular $S_{N} 2$ type reaction between the piperidine amide nitrogen and the benzylic carbon [26]. Similar mechanisms have been proposed for the benzyl migration of protonated peptides with Boc protecting groups [11]. These mechanisms are considered to be less plausible because an amide nitrogen is not considered to be a nucleophile [27].

Recently, ion-neutral complexes have been found to be involved in many gas-phase rearrangements [14]. Specifically, Harrison and co-workers have demonstrated that upon low-energy CID, fragmentations of protonated amide proceed by way of ion-neutral complexes [28]. Thus, it is reasonably proposed that the rearrangement of protonated 1 (a protonated amide) proceeds by way of ion-neutral complexes. As outlined in Scheme 3, when the piperidine amide group is protonated, the $\mathrm{C}-\mathrm{N}$ bond cleaves to form an ionneutral complex consisting of the b-type ion at $\mathrm{m} / \mathrm{z} 263$ and a neutral piperidine derivative. This complex can be facilitated by several non-covalent-bonding interactions (hydrogen bonding, charge-dipole, dipole-dipole, etc). Since many reactions and rearrangements may occur within ion-neutral complexes, it is proposed that in this complex, the rearrangement to form the ion at $\mathrm{m} / \mathrm{z} 357$ competes with the b-type ion at $\mathrm{m} / \mathrm{z} 263$ and the $y$-type ion at $m / z 267$. Namely, the piperidine amine acts as a nucleophile to attack the benzylic carbon of the $\mathrm{b}$-ion, and protonated ether of the b-ion acts as a leaving group, leading to the migration of the benzylic group to the piperidine amine to form the ion at $\mathrm{m} / \mathrm{z} 357$. Such a $\mathrm{S}_{\mathrm{N}} 2$ reaction is facilitated by the fact that piperidine is a very strong nucleophile with $\mathrm{n}_{\mathrm{CH} 3 \mathrm{I}}$ being 7.30 [29] and the fact that protonated ether, like protonated alcohol, is a gas-phase leaving group [30].

\section{CID of $d_{4}-1$}

The proposed ion-neutral-complex mechanism for protonated 1 was checked by MS/MS of $\mathrm{d}_{4}-\mathbf{1}$ at $\mathrm{m} / \mathrm{z} 533$ in which the four changeable protons (one amide and three amine protons) were replaced by deuterium. The six product ions for $\mathrm{d}_{4}-\mathbf{1}$ (not shown), observed at $\mathrm{m} / \mathrm{z}$ $447,358,269,266,238$, and 190, are consistent with the structures proposed for protonated 1 (see Scheme 1). However, it was observed that the rearrangement ion, both in an ion trap and in a collision cell of Q-TOF, shows significant isotopic scrambling. It is difficult to explain this isotopic scrambling by the mechanisms of either a concerted four-membered-ring intermediate [12] or a cyclic transition state [11]. However, a plausible explanation for this isotopic scrambling may be the existence of ion-neutral complexes in the rearrangement process. As is well documented, the most common

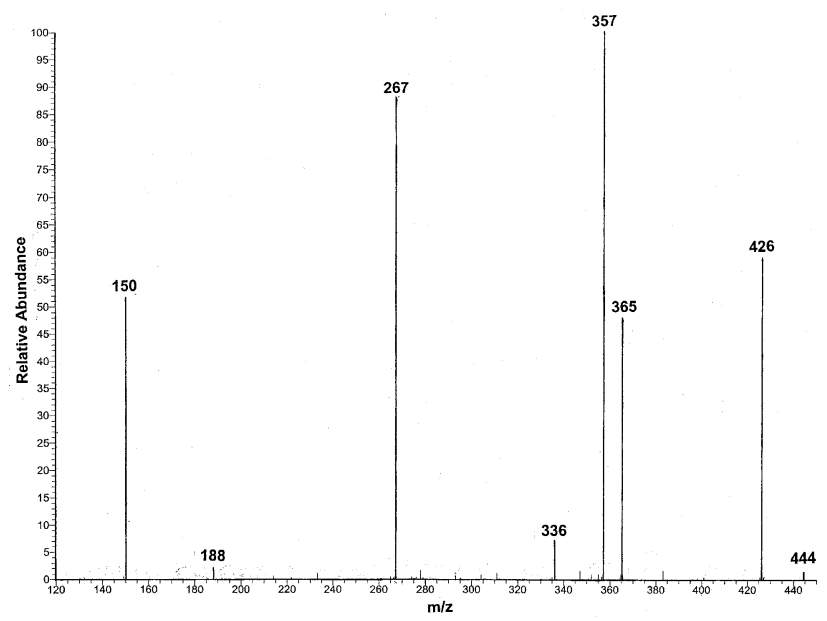

Figure 2. An ESI/MS/MS spectrum of protonated 2 obtained using Finnigan LCQ.

reactions occurring in ion-neutral complexes are $\mathrm{H}$ transfers and $\mathrm{H}$ exchanges [14], which can lead to isomerization and isotopic scrambling.

\section{CID of Protonated 2}

Protonated 2 (an analog of 1) was studied under the same experimental conditions to determine whether or not an analog of $\mathbf{1}$ undergoes the same rearrangement.

A representative MS/MS spectrum of protonated 2 obtained using Finnigan LCQ is depicted in Figure 2. The figure shows six major product ions at $m / z 426,365$, 357, 336, 267 and 150. The structures for these product ions are proposed in Scheme 4 . It is noteworthy that the
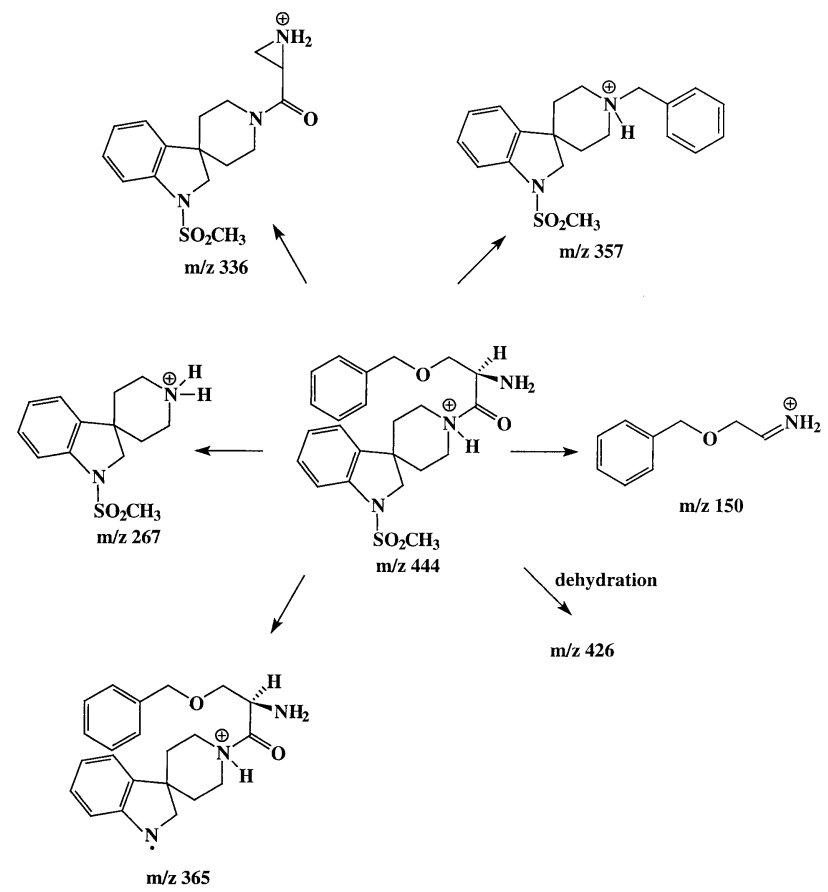

Scheme 4 Proposed structures for the six major product ions observed in MS/MS of protonated 2. 
same rearrangement ion at $\mathrm{m} / \mathrm{z} 357$ was indeed observed. This was verified by a comparison of the product ions of this ion (MS ${ }^{3}$ experiments) with the product ions of protonated 3 (MS ${ }^{2}$ experiments), as well as with the product ions of the ion at $m / z 357$ observed in CID of protonated $\mathbf{1}$ (MS ${ }^{3}$ experiments). The product ion at $\mathrm{m} / \mathrm{z} 365$ is formed by the elimination of the $\mathrm{SO}_{2} \mathrm{CH}_{3}$ radical from protonated 2 . The ion at $\mathrm{m} / \mathrm{z} 336$ is formed by the elimination of $\left(\mathrm{C}_{6} \mathrm{H}_{5}\right) \mathrm{CH}_{2} \mathrm{OH}$ from protonated 2 . This elimination is possibly facilitated by the participation of the neighboring amine group [27]. In fact, the loss of $\left(\mathrm{C}_{6} \mathrm{H}_{5}\right) \mathrm{CH}_{2} \mathrm{OH}$ was too weak to be seen in CID of protonated 1 that does not have a neighboring amine group. The ion at $\mathrm{m} / \mathrm{z} 267$ is a y-type ion, and the ion at $\mathrm{m} / \mathrm{z} 150$ is an a-type ion. These assignments are supported by accurate mass measurement using QTOF-2 (not shown). The product ion at $\mathrm{m} / \mathrm{z} 426$ is formed by dehydration $\left(-\mathrm{H}_{2} \mathrm{O}\right)$ from protonated 2 . An accurate mass obtained from QTOF-2 for this ion is $426.1888 \mathrm{Da}$, giving the relative error of $9 \mathrm{ppm}$ for dehydration (the actual mass is $426.1851 \mathrm{Da}$ ). Repeated measurements gave similar results. These results support the assignment for this ion. For protonated 2, the rearrangement competes with all these fragmentation processes.

Interestingly, there is a striking difference between the relative intensities of the rearrangement from protonated $\mathbf{1}$ and $\mathbf{2}$. The rearrangement is a minor process of protonated 1 (Figure 1) while it is a predominant process of protonated 2 (Figure 2). Since protonated $\mathbf{2}$ is also a product ion $(\mathrm{m} / \mathrm{z} 444)$ of protonated 1 , it may be argued that the rearrangement observed in CID of protonated 1 occurs consecutively from the ion at $\mathrm{m} / \mathrm{z}$ 444 rather than directly from protonated 1 . This was checked by a comparison of the intensity ratio (defined as the rearrangement ion to the ion at $\mathrm{m} / \mathrm{z} 444$ ) for protonated $\mathbf{1}$ and $\mathbf{2}$ under the same collision energies. It is assumed that the ratio for protonated $\mathbf{1}$ should be equal to or less than the ratio for protonated 2 if the rearrangement of protonated $\mathbf{1}$ is from a consecutive fragmentation of its product ion at $\mathrm{m} / \mathrm{z} 444$. It has been found that the ratio increases as collision energy increases. At higher collision energies, the ratio from protonated 1 can be much higher than the ratio from protonated 2. For example, at the collision energy of 45 $\mathrm{eV}$ using Micromass Q-TOF-2, the ratio was 9 from MS/MS of protonated 1 compared to 1 from MS/MS of protonated 2. Thus, direct rearrangement of protonated 1 under CID must contribute to some of the intensities of the rearranged ion. Nevertheless, the rearrangement is a minor process from protonated $\mathbf{1}$ whereas it is a major process from protonated 2.

The difference in relative intensity of the rearrangement ion for protonated 1 and 2 cannot be well explained by the mechanisms of a concerted four-membered-ring intermediate [12] or by a cyclic transition state [11] since the structural difference between protonated $\mathbf{1}$ and $\mathbf{2}$ is in the R-group (see Scheme 2), which is not in the reaction centers of these mechanisms. To

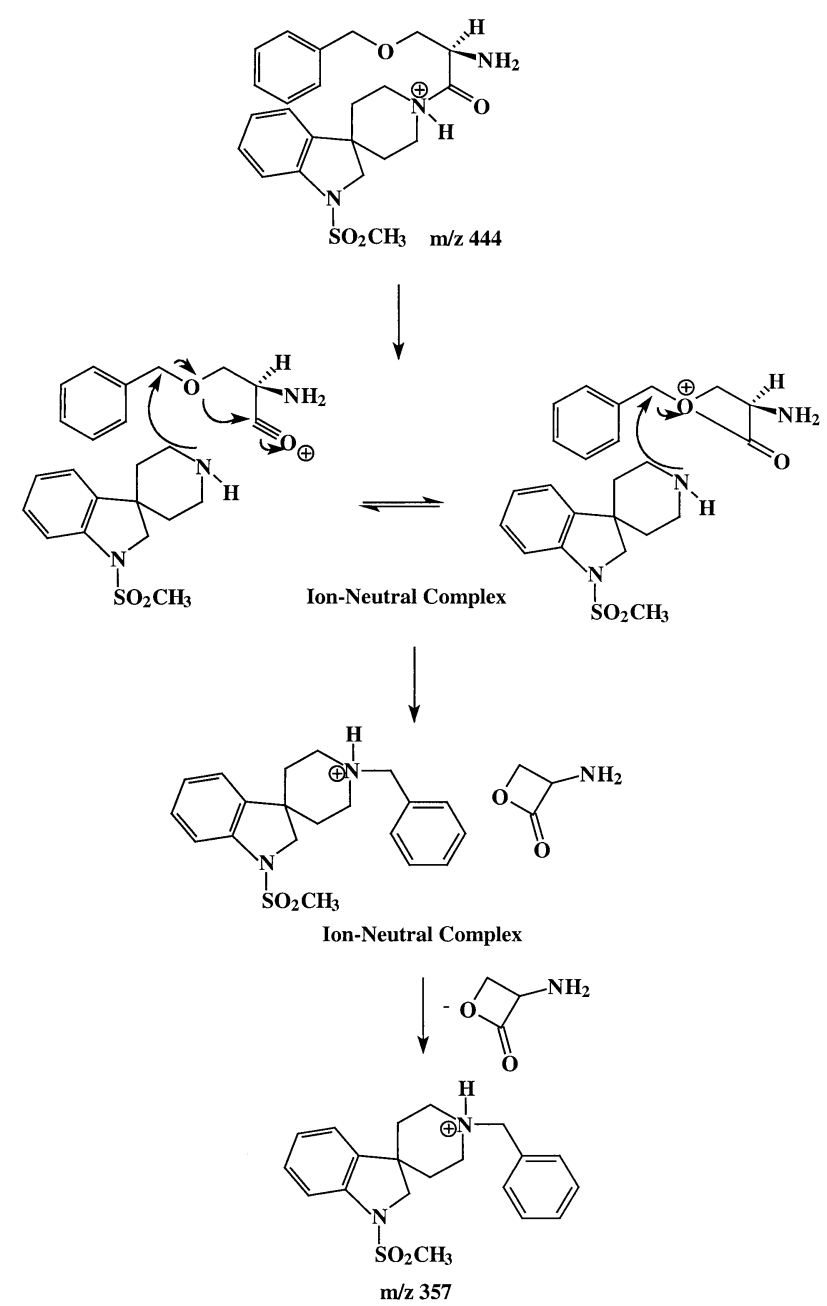

Scheme 5 A proposed rearrangement mechanism for the formation of the ion at $m / z 357$ from protonated 2 .

elaborate this point, several other species modified from 1 on the R-group have been made. It has been found that the relative intensity of the rearrangement ion could be dramatically affected by modifications of remote sites of the R-group, which further argues against these two mechanisms. On the other hand, the relative yield of the rearrangement ion for protonated $\mathbf{1}$ and $\mathbf{2}$ can be well explained by the proposed ion-neutral complex mechanism. Since the rearrangement is a $S_{N} 2$ type, it would be affected by both attacking nucleophiles and leaving groups. A comparison of the pathways for protonated 1 (Scheme 3) and 2 (Scheme 5) indicates that the neutral piperidine (the nucleophile) is the same, but the leaving groups of the two species are different. The leaving group for protonated $\mathbf{1}$ is a protonated ether group. Since the b-type ion in the ion-neutral complex formed from protonated $\mathbf{1}$ is an oxazolonium ion, the imine of which has a higher proton affinity (about $9.1 \mathrm{eV}$ ) than the ether group (about $8.1 \mathrm{eV}$ ), protonation of the ether group is less favored than that of the imine group. As a result, the rearrangement is a minor fragmentation process. On the 
other hand, the leaving group in the b-type ion in the ion-neutral complex formed from protonated $\mathbf{2}$ is likely an acylium cation or a positively charged lactone group (since an oxazolonium ion cannot be formed), which is a much better leaving group. Thus, a more facile rearrangement takes place. It has been found that when the R-group is modified so that the b-type ions cannot form oxazolonium ions, the rearrangement is a predominant process, and vice versa.

\section{Conclusion}

This study demonstrates that protonated $\mathbf{1}$ and $\mathbf{2}$ undergo a gas-phase rearrangement by a benzylic cation migration from an ether group to the piperidine amine. This rearrangement occurs during the cleavage of the piperidine amide bond of these two species in an ion trap or a quadrupole collision cell under low-energy CID. The rearrangement competes with the formations of $y^{-}, b-$ and/or a-type ions during the amide bond cleavage. It is proposed that the rearrangement proceeds as a nucleophilic displacement reaction in an ion-neutral complex. The study suggests that in the gas phase under certain conditions, an amine group formed from the cleavage of an amide bond in an amidecontaining species can be a nucleophile and undergo nucleophilic displacement reaction in an ion-neutral complex. The generality of this statement and the conditions under which such reactions can occur have yet to be further explored.

\section{Acknowledgments}

The author thanks Dr. Tsang-Lin Hwang of Merck for the NMR work on compound 3 and Pamela Thyng, Principal of English Solutions for proofreading the manuscript.

\section{References}

1. Murphy, M. G.; Weiss, S.; McClung, M.; Schnitzer, T.; Cerchio, K.; Connor, J.; Krupa, D.; Gertz, B. J. Clin. Endocrinol. Metab. 2001, 86(3) 1116-1125.

2. Dass, C. . Curr. Org. Chem. 1999, 3(2), 193-209.
3. Peng, S. X.; Branch, T. M.; King, S. L. . Anal. Chem. 2001, 73(3), $708-714$.

4. Qin, X. Z. J. Mass Spectrom. 1999, 34, 51-59.

5. Qin, X. Z.; Wu, Y.; Zhao, Z.; Chen, X. J. Mass Spectrom. 1999, 34, 733-740.

6. Zhao, Z.; Wang, Q.; Qin, X. Z.; Tsai, E. W.; Ip, D. P. J. Phar. Biomed. Anal. 1999, 20, 129-136.

7. Qin, X. Z.; Frech, P. J. Pharmaceut. Sci. 2001, 90, 833-844.

8. Qin, X. Z. . J. Mass Spectrom. 2001, 36(8), 911-917.

9. Constanzer, M. L.; Chavez-Eng, C. M.; Matuszewski, B. K. J. Chromatogr. B. Biomed. Sci. Appl. 1997, 693(1), 131-137.

10. McLafferty, F. W.; Turecek, F. Interpretation of Mass Spectra. University Science Books: Mill Valley, 1993; 4th ed.; 167.

11. Danieli, B.; Rubino, F. M.; Cremonesi, A. Organic Mass Spectrom. 1989, 24, 225-229.

12. Mammoliti, E.; Sindona, G.; Uccella, N. Org. Mass Spectrom. 1992, 27, 495-501.

13. Morton, T. H. J. Am. Chem. Soc. 1980, 102, 1596.

14. Longevialle, P. Mass Spectrom. Rev. 1992, 11, 157-192.

15. She, Y. M.; Liu, Z. Q.; Liu, S. Y. Gaodeng Xuexiao Huaxue Xuebao (University Chemistry Report). 1998, 19, 372-378.

16. Lesur, B.; Ducep, J.-B.; Lalloz, M.-N.; Ehrhard, A.; Danzin, C. Bioorg. Med. Chem. Lett. 1997, 7(3), 355-360.

17. Dongre, A. R.; Jones, J. L.; Somogyi, A.; Wysocki, V. H. J. Am. Chem. Soc. 1996, 118, 8365-8374.

18. Cox, K. A.; Gaskell, S. J.; Morris, M.; Whiting, A. J. Am. Soc. Mass Spectrom. 1996, 7, 522-531.

19. McLafferty, F. W.; Turecek, F. Interpretation of Mass Spectra; 4th ed. University Science Books: Mill Valley, 1993Table A.3.

20. Harrison, A. G. Org. Mass Spectrom. 1987, 22, 637.

21. Audier, H. E.; Monteiro, C.; Berthomieu, D.; Tortajada, J. Int. J. Mass Spectrom. Ion Processes 1991, 104, 145.

22. Polce, M. J.; Ren, D.; Wesdemiotis, C. J. Mass Spectrom. 2000, 35, 1391-1398.

23. Nold, M. J.; Wesdemiotis, C.; Yalcin, T.; Harrison, A. G. Int. J. Mass Spectrom. Ion Processes 1997, 164, 137-153.

24. McLafferty, F. W.; Turecek, F. Interpretation of Mass Spectra, 4th ed.; University Science Books: Mill Valley, 1993; p 238.

25. Williams, D. H. Acc. Chem. Res. 1977, 10, 280.

26. Qin, X. Z. Proceedings of the 47th ASMS Conference on Mass Spectrometry and Allied Topics; 1999; Sesson code: TPB, slot: 036.

27. March, J. Advanced Organic Chemistry, 4th ed.; Wiley Interscience: New York, 1992; pp 293-339.

28. Tu, Y. P.; Harrison, A. G. J. Am. Soc. Mass Spectrom. 1998, 9(5), $454-462$.

29. Pearson, R. G.; Sobel, H.; Songstad, J. J. Am. Chem. Soc. 1963, 90, 319.

30. Reid, G. E.; Simpson, R. J.; O'Hair, R. A. J. J. Am. Soc. Mass Spectrom. 2000, 11(12), 1047-1060. 